\title{
Liggaamsoriëntasie van blesbokke in 'n skadulose omgewing
}

C.H.J. van Aswegen* en O.B. Kok

Departement Dierkunde, Universiteit van die Oranje-Vrystaat, Posbus 339, Bloemfontein 9300

Ontvang 2 April 199l; aanvaar 25 Julie 199l

\section{UITTREKSEL}

Ondersoek is ingestel na die liggaamsoriëntasie van die blesbok Damaliscus dorcas phillipsi ten opsigte van sonshoek en windrigting in 'n skadulose omgewing in die sentrale Oranje-Vrystaat. Gedurende die vroeë oggend en laat middag wanneer die sonshoogte en omgewingstemperatuur relatief laag is, oriënteer die bokke klaarblyklik lateraal ten opsigte van die son. Namate die temperatuur gedurende die middel van die dag toeneem, toon die bokke 'n neiging om in lyn met die inkomende sonstrale, maar lateraal ten opsigte van die windrigting, te oriënteer.

\section{ABSTRACT}

\section{Body orientation of blesbok in a shadeless environment}

The body orientation of blesbok Damaliscus dorcas phillipsi in relation to sun angle and wind direction was investigated in a shadeless environment in the central Orange Free State. During early morning and late afiernoon, when the sun's altitude and ambient temperature are relatively low, the antelope evidently orientate laterally towards the sun. As the temperature increases during midday, the antelope show a tendencey to orientate in line with the incoming radiation but laterally in relation to wind direction.

*Huidige adres van outeur aan wie korrespondensie gerig kan word:

Departement Geografie, Vista Universiteit, Posbus X050, Vanderbijlpark 1900. 


\section{INLEIDING}

Vanaf die vroegste tye is die blesbok Damaliscus dorcas phillipsi hoofsaaklik tot die sentrale gedeeltes van SuidAfrika beperk. ${ }^{1.23}$ As grasvreters is hulle voorkeurhabitat grasvlaktes met of sonder klein bome en struike. ${ }^{4}$ Hierdie streke is dikwels aan grootskaalse seisoenale en selfs daaglikse variasie in klimaatstoestande blootgestel $.^{5} \mathrm{Hoe}-$ wel dit bekend is dat blesbokke die skaduwee van bome of bosse gedurende die somerhitte opsoek, ${ }^{3.6 .7}$ is sulke skaduplante nie altyd in dele van die Oranje-Vrystaat wat deur oop, uitgestrekte grasvelde gekenmerk word, beskikbaar nie. In hierdie studie is ondersoek ingestel na die verband tussen die sonshoek, windrigting en liggaamsoriëntering van blesbokke in 'n skadulose omgewing.

\section{STUDIEGEBIED}

Die studie is op die plaas Bethel $\left(29^{\circ} 03^{\prime} \mathrm{S} ; 26^{\circ} 29^{\prime} 0\right)$ in die sentrale gedeelte van die Oranje-Vrystaat uitgevoer. Volgens Acocks $^{8}$ val die gebied in die sentrale variasie van die droë Cymbopogon-Themeda-veldtipe (nr. 50b). Gebaseer op klimatologiese gegewens van die weerkantoor op die J.B.M. Hertzog-lughawe, ongeveer $30 \mathrm{~km}$ wes van die plaas, word warm, sonnige somers met ' $n$ gemiddelde temperatuur van $22,6^{\circ} \mathrm{C}$ in Januarie in die streek ondervind. Tydens die droë, koue wintermaande (MeiSeptember) daal die temperatuur in Julie tot ' $n$ gemiddeld van $7,0^{\circ} \mathrm{C}$. Nagnoeg 120 rypdae per jaar kom gedurende April-Oktober voor. Met 'n hoogte bo seespieël wat 1400 $m$ oorskry, word ' $n$ jaarlikse gemiddelde reënval van 560 $\mathrm{mm}$ in die gebied ondervind waarvan amper die helfte in die tydperk Januarie-Maart voorkom.

\section{METODES}

Veldwerk is tot 'n afgekampte gebied van 200 ha met 'n bevolking van 40 blesbokke beperk. Altesaam 1228 waarnemings van die liggaamsoriëntasie van blesbokke is oor 'n tydperk van 50 afsonderlike ure op 11 Junie, 28 Julie, 15 September en 3 Desember 1986 gemaak. In navolging van Berry et al..$^{9}$ is die onderstaande besonderhede op 'n uurlikse basis van sonop tot sononder tydens elke opname aangeteken: (i) Hoek tussen die oorlangse oriëntering van die bok en die magnetiese noorde $\left(0^{\circ}\right)$ deur een van agt vektore $\left(0^{\circ}-45^{\circ}, 45^{\circ}-90^{\circ}\right.$, deur tot $\left.360^{\circ}\right)$ aan elke individu toc te ken.

(ii) Windrigting met behulp van 'n weerhaan, deur dieselfde vektore te gebruik, en windspoed soos deur 'n Windual anemometer bepaal en uitgedruk in $\mathrm{ms}^{\text {'. }}$

(iii) Ongeskermde temperatuur deur van 'n gekleurde termometer (skakering 5YR, waarde 3, chroma 4 volgens Munsell se grondkleurkaarte) gebruik te maak om die velkleur van blesbokke sodoende na te boots.

(iv) Direkte sonlig of sonverdonkering weens bewolktheid.

(v) Blesbokke bewegend of stilstaande.

Bepaling van die vektorgemiddeld of resultante hoek van oriëntering (a) is gebaseer op die formule van $\mathrm{Zar}^{10}$ naamlik

$$
\begin{aligned}
& \operatorname{Cos} \overline{\mathrm{a}}=\frac{X}{r} \text { en } \sin \overline{\mathrm{a}}=\frac{Y}{r} \\
& \text { waar } X \text { (die } 0^{\circ} \text {-komponent) }=\frac{\sum_{i=1}^{n} \cos \mathrm{a}_{i}}{n} \\
& \text { en } \left.Y \text { (die } 90^{\circ} \text {-komponent }\right)=\frac{\sum_{i=1}^{n} \sin \mathrm{a}_{i}}{n} \\
& r \text { (die grootheid) }=\sqrt{X^{2}+Y^{2}}
\end{aligned}
$$

en die $a_{i}$ 's die middelpunte van die agt onderskeie waarnemingsvektore verteenwoordig. Ontleding van die resultate word in tabel $\mathbf{l}$ as voorbeeld uiteengesit.

Die onderstaande formules is vir die berekening van sonshoogte $\left(U_{1}\right)$ en -asimut $\left(U_{2}\right)$ gebruik.

$$
\begin{aligned}
& U_{1}=\sin ^{-1}(\sin P \times \sin D+\cos P \times \cos D \times \cos H) \\
& U_{2}=\cos ^{-1} \frac{\left(\sin D-\sin P \times \sin U_{1}\right)}{\cos P \times \cos U_{1}}
\end{aligned}
$$

waar $\mathbf{P}=$ breedtegraad van studiegebied

$\mathrm{D}=$ deklinasie van die son vir ' $\mathrm{n}$ bepaalde dag

TABEL 1

Verwerkingswyse en algemene statistiek vir die bepaling van die voorkeuroriëntasie van 28 blesbokke ten opsigte van sonshoek en windrigting soos op 11 Junie 1986 bepaal

\begin{tabular}{c|c|c|c|c|c|c|c|c|c}
\hline Tyd & $\begin{array}{c}\text { Kompo- } \\
\text { nent } \\
0^{\circ}\end{array}$ & $\begin{array}{c}\text { Kompo- } \\
\text { nent }\end{array}$ & $\begin{array}{c}\text { Grootheid } \\
90^{\circ}\end{array}$ & $\begin{array}{c}\text { Vektor- } \\
\text { sterkte }\end{array}$ & $\begin{array}{c}\text { Resul- } \\
\text { tante } \\
\text { hoek } \\
\text { (grade) } \\
(\bar{a})\end{array}$ & $\begin{array}{c}\text { Sons- } \\
\text { hoek } \\
\text { (grade) }\end{array}$ & $\begin{array}{c}\text { Verskil } \\
\text { tussen } \\
\text { S en } \bar{a} \\
\text { (grade) }\end{array}$ & $\begin{array}{c}\text { Wind- } \\
\text { rigting } \\
\text { (grade) }\end{array}$ & $\begin{array}{c}\text { Verskil } \\
\text { tussen } \\
\text { W en } \bar{a} \\
\text { (grade) }\end{array}$ \\
\hline $7: 00$ & 0,77 & $-13,38$ & 13,82 & 0,49 & 273,3 & - & - & 67,5 & 205,8 \\
$8: 00$ & $-12,08$ & $-6,85$ & 13,89 & 0,50 & 209,6 & 56,5 & 153,1 & 22,5 & 187,1 \\
$9: 00$ & $-0,77$ & 2,61 & 2,72 & 0,10 & 106,3 & 46,9 & 59,4 & 22,5 & 83,8 \\
$10: 00$ & $-7,07$ & 3,38 & 7,84 & 0,28 & 154,5 & 35,0 & 119,5 & 22,5 & 132,0 \\
$11: 00$ & $-9,46$ & 17,30 & 19,72 & 0,70 & 118,7 & 20,3 & 98,4 & 22,5 & 96,2 \\
$12: 00$ & 0,58 & 17,71 & 17,72 & 0,63 & 88,1 & 3,4 & 84,7 & 22,5 & 65,6 \\
$13: 00$ & 18,45 & $-5,86$ & 19,36 & 0,69 & 342,4 & 346,1 & 3,7 & 22,5 & 319,9 \\
$14: 00$ & $-9,95$ & $-25,86$ & 27,71 & 0,99 & 291,0 & 330,5 & 39,5 & 22,5 & 268,5 \\
$15: 00$ & $-18,16$ & $-0,77$ & 18,18 & 0,65 & 182,4 & 317,5 & 135,1 & 22,5 & 159,9 \\
$16: 00$ & $-9,82$ & $-16,31$ & 19,04 & 0,68 & 239,0 & 307,1 & 68,1 & 22,5 & 216,5 \\
$17: 00$ & 7,21 & 5,99 & 9,37 & 0,33 & 39,7 & 298,1 & 258,9 & 157,5 & 117,8 \\
\hline
\end{tabular}


$\mathbf{H}=$ uurhoek van die son op 'n bepaalde tydstip van waarneming (verskil in lengtegraad tussen die posisie van die son en die studiegebied).

Deur van 'n eenvoudige rekenaarkode en sterrekundige almanak gebruik te mak, kon die sonshoogte en -asimut vir elke uur van waarneming bereken word.

\section{RESULTATE}

\section{Midwinter}

Tydens die Julie-opname het die blesbokke 'n duidelike neiging getoon om vroegdag in 'n stilstaande posisie loodreg $\left(90^{\circ} / 270^{\circ}\right)$ ten opsigte van die sonstrale te oriënteer (fig. 1). Hierdie tendens het voortgeduur totdat 'n temperatuur van $19^{\circ} \mathrm{C}$ teen 11:00 bereik is. By hoër temperature gedurende die middel van die dag het die bokke afwisselend met die kop of stert direk na die son georiënteer. ' $n$ Toename in beweeglikheid, hetsy deur te stap of te wei, het terselfdertyd voorgekom. Namate die temperatuur teen laat middag begin daal het, het die bokke weer cens breedsy na die son georiënteer.

In teenstelling met die voorafgaande oriëntasiepatroon ten opsigte van die sonshoek, het die blesbokke merendeels 'n breedsyposisie met betrekking tot windrigting in die ooreenstemmende tydperk gehandhaaf (fig. 2). Die enigste uitsonderings was gedurende die vroeë oggend en teen 13:00 toe geen windspoed geregistreer kon word nie.
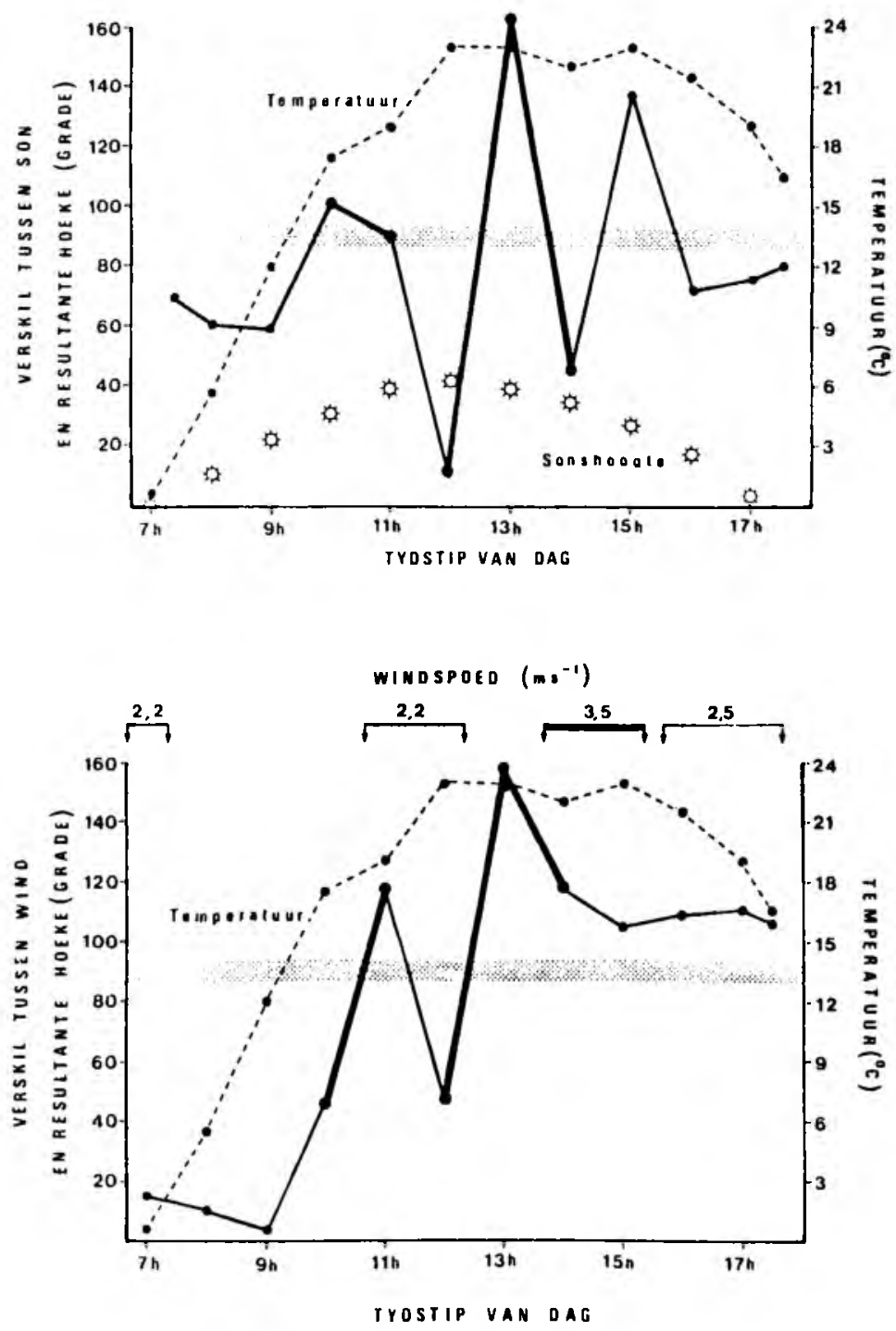

\section{Voorsomer}

Met die aanvang van die lentetydperk het die meeste blesbokke al bewegend ' $n$ breedsyposisie ten opsigte van die son gedurende die eerste paar uur na sonop ingeneem (fig. $3)$. Soos met die winteropname het 'n parallelle oriëntasie eers gedurende die middel van die dag voorgekom nadat 'n temperatuur van $18^{\circ} \mathrm{C}$ bereik is. In hierdie tydperk het feitlik alle bewegende of stilstaande individue hulle agterstewes na die son gerig. Teen laat middag het 'n daling in temperatuur weer gepaardgegaan met 'n sywaartse oriëntering ten opsigte van die ondergaande son.

Wat die windaspek betref, het die blesbokke vir die grootste gedeelte van die betrokke dag 'n parallelle oriëntasie, stert na wind, gehandhaaf (fig. 4). Slegs by twee geleenthede is ' $n$ besliste voorkeur aan 'n breedsyposisie gegee, en wel teen 15:00 toe die hoogste temperatuurlesing geregistreer is, en teen sononder toe die temperatuur en windspoed skerp gedaal het.

\section{Midsomer}

Soos in die vorige gevalle het die blesbokke gedurende die vroeë oggend (5:00-8:00) 'n breedsyposisie ten opsigte van die somerson ingeneem (fig. 5). Gedurende die res van die dag, toe maksimum temperature van nagenoeg $32^{\circ} \mathrm{C}$ bereik is voordat bewolkte toestande 'n skerp daling in temperatuur teweeggebring het, het die bokke afwisselend met die kop, stert of sykant na die son georiënteer. Statiese ak-
FIGUUR I: Voorkeuroriëntering van blesbokke ten opsigte van sonshoek soos op 28 Julie 1986 in die sentrale Oranje-Vrystaat bepaal. $0^{\circ}$, front na son; $180^{\circ}$, stert na son; $90^{\circ}$ (gearseerde strook), sykant na son; breë volstreep, blesbokke bewegend; smal volstreep, blesbokke stilstaande.
FIGUUR 2: Voorkeuroriëntering van blesbokke ten opsigte van windrigting soos op 28 Julie 1986 in die sentrale Oranje-Vrystaat bepaal. $0^{\circ}$, front na wind; $180^{\circ}$, stert na wind; $90^{\circ}$ (gearseerde strook), sykant na wind; breё volstreep, blesbokke bewegend; smal volstreep, blesbokke stilstaande. 

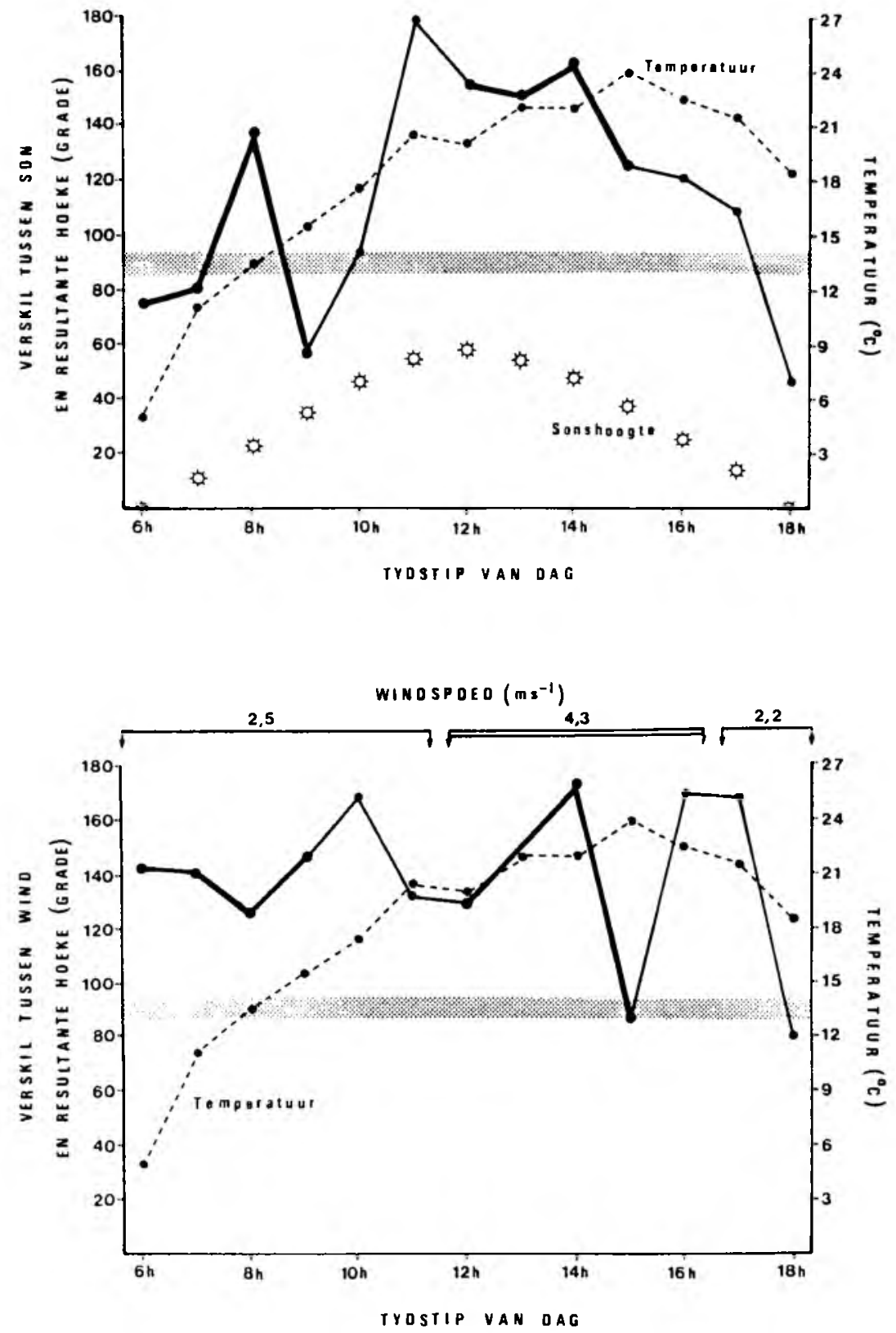

FIGUUR 3: Voorkeuroriëntering van blesbokke ten opsigte van sonshoek soos op 15 September 1986 in die sentrale OranjeVrystaat bepaal. $0^{\circ}$, front na son; $180^{\circ}$, stert na son; $90^{\circ}$ (gearseerde strook), sykant na son; breë volstreep, blesbokke bewegend; smal volstreep, blesbokke stilstaande.
FIGUUR 4: Voorkeuroriëntering van blesbokke ten opsigte van windrigting soos op 15 September 1986 in die sentrale OranjeVrystaat bepaal. $0^{\circ}$, front na wind; $180^{\circ}$, stert na wind; $90^{\circ}$ (gearseerde strook), sykant na wind; breë volstreep, blesbokke bewegend; smal volstreep, blesbokke stilstaande.

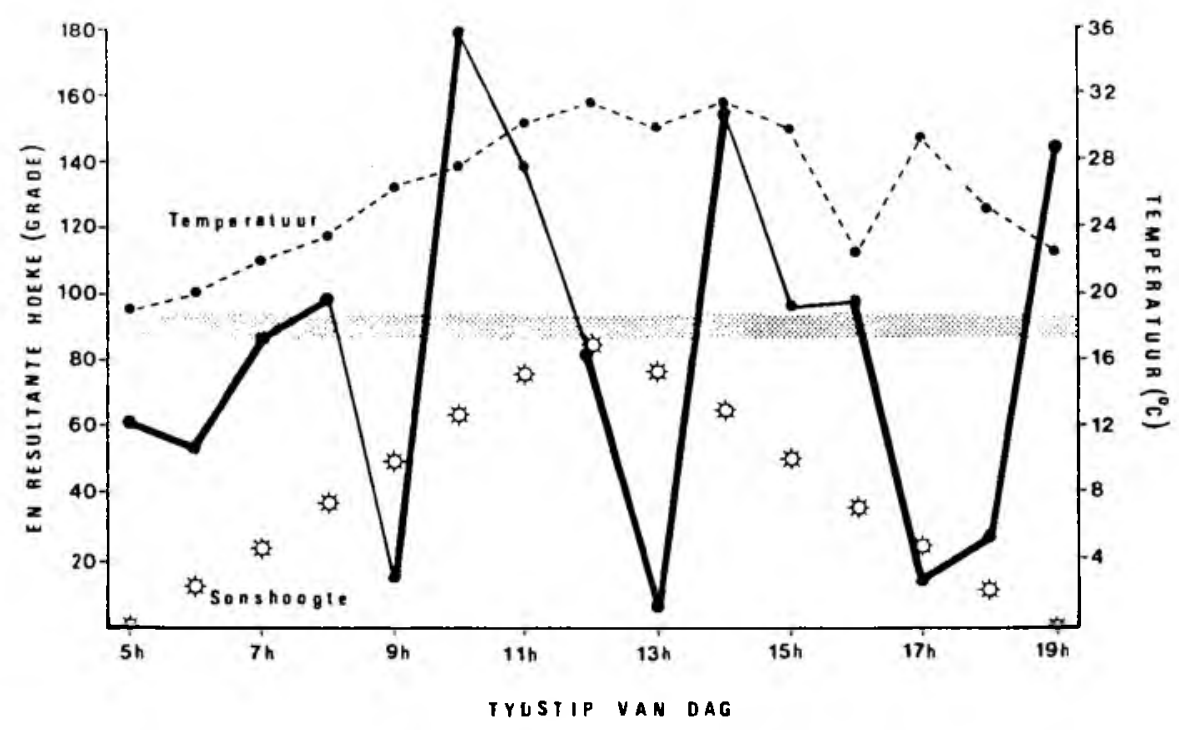

FIGUUR 5: Voorkeuroriëntering van blesbokke ten opsigte van sonshoek soos op 3 Desember 1986 in die sentrale OranjeVrystaat bepaal. $0^{\circ}$, front na son; $180^{\circ}$, stert na son; $90^{\circ}$ (gearseerde strook), sykant na son; breë volstreep, blesbokke bewegend; smal volstreep, blesbokke stilstaande. 
tiwiteite is ook deur die loop van die dag deur periodes van beweeglikheid afgewissel.

'n Teenoorgestelde patroon van oriëntasie is in die ooreenstemmende tydperk ten opsigte van windrigting gehandhaaf. Soos blyk uit figuur 6 het die blesbokke aanvanklik direk (of met die stert) na die wind gefront. Dit het saamgeval met 'n heersende windspoed van tot $6,7 \mathrm{~ms}$ '. Met enkele uitsonderings het die bokke tydens die res van die dag aan 'n breedsyposisie voorkeur gegec. Laasgenoemde tydperk het saamgeval met 'n afname in windspoed.

\section{BESPREKING}

Nieteenstaande die feit dat veldwaarnemings onder verskillende omstandighede in verskillende seisoene van die jaar uitgevoer is, stem die reaksie van bleshokke met betrekking tot die sonshoek merkwaardig ooreen. Tydens al drie opnames het die bokke vroegdag met hul lengte-as loodreg na die son georiënteer. Die eerste paar uur na sonop verteenwoordig 'n tydperk wanneer die sonshoogte en omgewingstemperatuur relatief laag is, veral tydens die koue wintermaande. Deur die grootste oppervlakte van die liggaam dus aan inkomende sonstrale bloot te stel, word hitteopname grootliks vergemaklik. Soortgelyke gedrag is vir die Thomsongasel Gazella thomsoni gerapporteer. "

Namate die omgewingstemperatuur gedurende die middel van die dag toeneem, toon die bokke 'n besliste neiging om hul lengte-as parallel ten opsgite van die son te oriënteer. Deur die kleinste oppervlakte van die liggaam aan direkte sonstrale bloot te stel, kan oormatige hittelading gedurende die warmste tyd van die dag dus tot 'n groot mate voorkom word. ${ }^{12}, 13$ In hierdie opsig is die kopomlaag-houding van blesbokke veral kenmerkend, ${ }^{7}$ want met hul lateraal afgeplatte nek en skouers, kort hare en glansende pels vind 'n hoë mate van reflektiwiteit plaas. ${ }^{13 .}{ }^{14}$ Termoregulering kan egter ook bevorder word deur die invalshoek van die son op die liggaamsoppervlakte te varieer. Die groter mate van beweeglikheid tydens die somermaande $(64,3 \%$ teenoor die $27,3 \%$ van die wintermaande), indirek veroorsaak deur die verhoogde kwaliteit van beskikbare voedsel, ${ }^{15}$ is in hierdie opsig veelseggend.

Soos deur Berry et al. ${ }^{9}$ vermeld, behoort oriënteringsdata ten opsigte van die sonshoek versigtig geïnterpreteer te word. Gedurende Desember bereik die son naamlik 'n hoogte van ongeveer $83^{\circ} \mathrm{C}$ in die studiegebied. Dit beteken dat weinig rigtinggewende inligting op die horisontale vlak gedurende die middel van die dag deur die son verskaf word. Op die hitte van die dag behoort liggaamsoriëntasie dus min verband met die oorhoofse posisie van die son te toon. In hierdie opsig speel wind waarskynlik 'n belangrike rol by termoregulering. Dit blyk veral uit die oorwegend breedsyposisie ten opsigte van die windrigting wat vir groot dele van die dag deur die blesbokke gehandhaaf word. Oor die algemeen word verhoogde windspoed juis met die warmste tye van die dag geassosieer. Maksimale blootstelling aan lugstroming, waardeur effektiewe afkoeling teweeggebring kan word, word sodoende verseker. ${ }^{4}{ }^{16}$ Dit moet egter in gedagte gehou word dat wind ook 'n belangrike funksie as vektor van geluide en reuke vervul waardeur bykomende inligting aangaande die omgewing aan diere beskikbaar gestel word. 9,15 Opsommend wil dit dus voorkom asof 'n kombinasie van faktore eerder as 'n enkele aspek die liggaamsoriëntasie van blesbokke in 'n skadulose omgewing beïnvloed.

\section{DANKBETUIGINGS}

Dank is verskuldig aan mnr. G.J. Malcolm vir die verskaffing van sterrekundige gegewens, dr. J.M. van Zyl en proff. J.S. le Roux en E.N. Mullins vir advies met betrekking tot die verwerking van data, mnr. C.A. van Ee vir die voorbereiding van figure en mnr. C.H.J. van Aswegen vir toestemming om die studie op sy plaas te kon uitvoer. Die Universiteit van die Oranje-Vrystaat en Universiteit Vista word vir gedeeltelike finansiële steun bedank.

\section{LITERATUURVERWYSINGS}

1. Du Plessis, S.F. (1969). The past and present geographical distribution of the Perissodactyla and Artiodactyla in South Africa. (M.Sc.dissertation Univ. Pretoria).

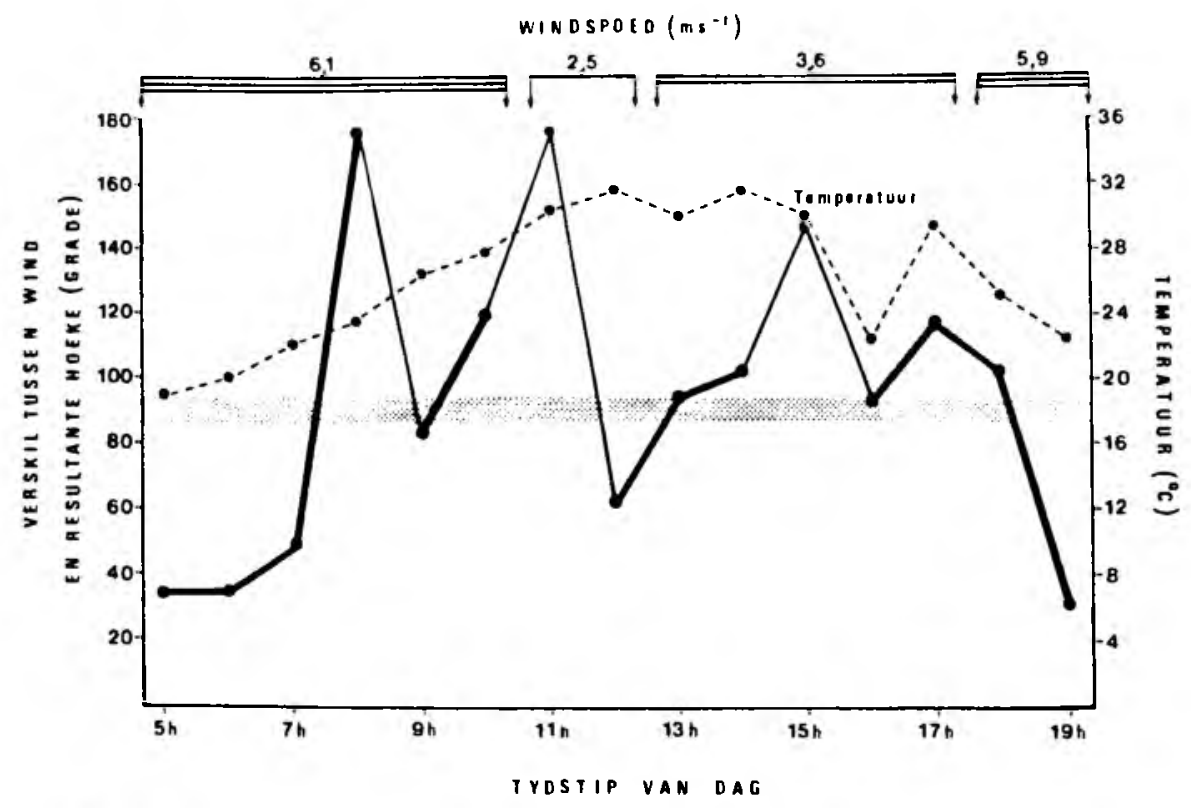

FIGUUR 6: Voorkeuroriëntering van blesbokke ten opsigte van windrigting soos op 3 Desember 1986 in die sentrale OranjeVrystaat bepaal. $0^{\circ}$, front na wind; $180^{\circ}$, stert na wind, $90^{\circ}$ (gearseerde strook), sykant na wind; breë volstreep, blesbokke bewegend; smal volstreep, blesbokke stilstaande. 
2. Skead, C.J. (1987). Historical mammal incidence in the Cape Province. Vol. 1 \& 2 (Dept. of Nature and Environmental Conservation, Cape Town).

3. Skinner, J.D. \& Smithers, R.H.N. (1990). The mammals of the Southern African subregion (Univ. Pretoria, Pretoria).

4. Haltenorth, T. \& Diller, H. (1980). A field guide to the mammals of Africa including Madagascar (Collins, London).

5. Anon. (1986). Klimaat van Suid-Afrika. Klimaatstatistieke tot 1984. WB 40, Dept. van Omgewingsake (Staatsdrukker, Pretoria).

6. Du Plessis, S.S. (1968). Ecology of blesbok (Damaliscus dorcas phillipsi) on the Van Riebeeck nature reserve, Pretoria, with special reference to productivity (D.Sc.-thesis, Univ. Pretoria).

7. Lynch, C.D. (1974). A behavioural study of blesbok, Damaliscus dorcas phillipsi, with special reference to territoriality, Mem. Nas. Mus., 8, $1-83$.

8. Acocks, J.P.H. (1988). Veld types of South Africa, Mem. bot. surv: S. Afr., 57, 1-146.

9. Berry, H.H., Siegfried, W.R. \& Crowe, T.M. (1984). Orientation of wildebeest in relation to sun angle and wind direction, Madoqua, 13, 297-301.

10. Zar, J.H. (1974), Biestatistical analysis (Prentice-Hall, New Jersey).

II. Walther, F. (1973). Round-the-clock activity of Thomson's gazelle (Gazella thomsoni Günther, 1884) in the Serengeti National Park, T. Tierpsychol., 32, 75-105).

12. David, J.H.M. (1973). The behaviour of the bontebok, Damaliscus dorcas dorcas (Pallas 1766), with special reference to territorial behaviour., Z. Tierpsychol, 33, 38-107.

13. Jarman, P.J. (1977). Behaviour of topi in a shadeless environment, Zool. Afric., 12, 101-111.

14. Hofmeyr, M.D. (1985). Thermal properties of the pelages of selected African ungulates, $S$. Afr. $J$. Zool., 20, 179-189.

15. Leuthold, W. (1977). African ungulates: A comparative review of their ethology and behavioural ecology (Springer-Verlag, Berlyn).

16. Brooks, A.C. (1961). A study of the Thomson's gazclle (Gazella thomsonni Günther) in Tanganyika, Colon. Res. Publs., 25, 147. 